\title{
DIALOGUE IS A SIGN OF CONSTRUCTIVENESS IN MEDIATION
}

\author{
*Viktorija Portere ${ }^{1}$, Vladimirs Morevs ${ }^{2}$ \\ ${ }^{1}$ Latvia University of Life Sciences and Technologies, Latvia \\ 2"PRIVUS" Ltd, Latvia \\ *Corresponding author's email: viktorija.portere@gmail.com
}

\begin{abstract}
Dialogue (discourse) is the main indication leading us to the conclusion that mediation is constructive. Discourse, the main form of dialogue, allows to achieve a positive result of mediation - an agreement between the participants of the conflict, as well as to learn dialogue communication skills. The aim of this study is to determine the types of dialogue used in mediation, the usage of recognized dialogue, and to find methods for assessing the dialogue (discourse) skills that need to be taught to the participants of the conflict, as well as future mediators and to evaluate the effectiveness of mediation. The research was conducted based on the theoretical methods of analysis of modern concept of dialogue and empirical testing methods (using questionnaires) of the participants of the conflicts and future mediators. Methods of mathematical statistics were used, when processing and analyzing the results of the questionnaires. As a result of this work, the types of dialogue used in mediation are identified, recommendations on the choice of components and barriers of dialogue to be considered by the mediator when training participants in the conflict and future mediators are made, as well as recommendations on assessment the effectiveness of mediation are offered.
\end{abstract}

Key words: types of dialogue, discourse, constructive mediation, construct.

\section{Introduction}

The dialogue is considered to be the key attribute of the constructive mediation. Mediation is aiming not only to solve the conflict but also to give the participants of the conflict the skills not to enter into a new conflict by teaching them the rules of dialogue, as the development model of society is based on the principle of harmony between the society and nature, cultural and civilization processes emplacing dialogical interaction (Yermolayeva, 2015). The field of applying the mediation is expanding due to continuously increasing importance of informal relationships and interpersonal connections in the life of society, growing numbers of legal regulations, governing the society, and their mutual inconsistency, as well as scientific and technological progress. There are more and more opportunities for various interpretations of conflict resolution methods.

Dialogue when translated literally from Greek is a speech (conversation) between two persons. The concept of dialogue developed from the existing everyday interpretation, when the dialogue is a written or spoken conversational exchange between two or more people, and a literary and theatrical form that depicts such an exchange, to the main form of communication between people who exchange not only words but signs that are intonations, in which these words are spoken, the actions of the dialogue subject, its silence and gestures.

It is teaching dialogue and using it as one of the main methods of counselling (Soika, 2015) in conducting mediation, changing the existing 'construct', that led to conflict, or creating a new 'construct' is the main characteristics of constructive mediation. The constructive approach is largely owing to the concept of 'construct'. This concept gives an explanation and the name of this approach.
G. Kelly, the American psychologist, gave one of the most successful definitions of this concept: 'Man looks at his world through transparent patterns or templates which he creates, and then attempts to fit over the realities of which the world is composed. The fit is not always very good. Yet without such patterns, the world appears to be such an undifferentiated homogeneity that man is unable to make any sense out of it.... Let us give the name constructs to these patterns' (Kelly, 1991).

Historically, the direction of constructivism, which recognized the primary role of dialogue, is called social constructivism: 'This is a direction that recognizes the main role of discourse as a type of dialogue in the relationship between people in the world and their own 'I' construction, the need to abandon ideas about universal absolute truths, behavior standards, considering the psychological processes taking place in a person concerning the culture and history of specific communities, calling for voices and mutual enrichment of various discourses (languages and ways of interpreting the world), democratization and social transformation of people's consciousness' (Ulanovsky, 2009).

The discursive psychology, the founder of which was H.R. Harre, deserves our attention in social constructivism. In 1987, the work of J. Potter and M. Wetherell 'Discourse and Social Psychology: Beyond Attitudes and Behavior', Dialogical Self Theory of H.J.M. Hermans became fundamental in this direction. M. Bahtin, M. Buber, D. Bohm made a major contribution to the philosophical understanding of the concept of dialogue, an analysis of its historical development, an analysis of dialogue (discourse) development in communication in society - J. Habermas, the author of the Discourse Ethics or Communication Ethics. 
The dialogue, its philosophy, components, and barriers in mediation, as well as types of mediation, are discussed also in the article Importance of Dialogue Nature in the Mediator's Competence (Portere \& Briede, 2019).

Using existing approaches and interpretations of the concept of dialogue, the accumulated practical experience, competent performance (Adler \& Pouliot, 2011), and the results of conducting numerous mediations, the aim of the study is to identify the types of dialogue used in mediation, to use one of the types of dialogue- recognizing dialogue to find methods for assessing the skills of dialogue ( discourse) that need to be taught to the participants of the conflict, as well as future mediators and assess the effectiveness of mediation article will determine the types of dialogue used in the mediation.

In order to extract the types of dialogue used in mediation, there is a need to analyze history of this concept, the use and development of it by the above researchers.

\section{Materials and Methods}

One of the research methods used in this study is a theoretical analysis of the dialogue description given in the works of the most important authors from the point of this study, first of all above mentioned constructivists, as well as analysis of existing approaches and interpretations of the concept of dialogue. Also, an empirical method such as questioning of the parties to the conflict and future mediators, as well as methods of mathematical statistics for processing the results of the survey have been used.

The types of dialogs in mediation

The history of this concept of dialogue was analyzed by $\mathrm{M}$. Bahtin, a famous ideologist of dialogue, whose work was accompanied by the statement 'to be means to communicate dialogically’ (Bahtin, 1979).

Researching the 'Socratic Dialogue' M. Bahtin wrote: 'Socratic Dialogue is a special and widespread genre in its time. At the base of the genre lies the Socratic notion of the dialogic nature of truth, and the dialogic nature of human thinking about truth... Truth is not born nor it is to be found inside the head of a person, it is born between people collectively searching for truth, in the process of their dialogic interaction. Socrates called himself a 'pander': he brought people together and made them collide in a quarrel, and as a result, truth was born' (Bahtin, 1979).

M. Bahtin emphasized the following methods of Socratic dialogue:

o syncrisis - a comparison of different points of view on a particular subject;

o anacrisis - ways to provoke the words of the interlocutor, make him express his opinion to the end; o diatribe - a rhetorical genre of dialogue, usually constructed in the form of conversation with absent interlocutor;

o soliloquium - dialogical attitude to oneself, that is, a conversation with oneself.

For this purpose, the dialogue plot situation can be used.

Next, let us consider the main ideas that can also be taken from the previously named authors to achieve the desired goal.

It is important for this research to discuss the Dialogical Self Theory by H.J.M. Hermans. The main idea of this theory is based on the understanding of the human self as a dynamic set of 'I-positions'.

'By I-position one understands various roles, self-expression, it is also others in me - images of surrounding people, voices and characters typical for this or another culture. Position is also animals, objects, cultural symbols, nature, God or nature. Position is a relatively autonomous subject which possesses its own voice, world-view, ability to respond' (Hermans, 2012).

That is, the human 'I' represents a variety of positions that are in the process of change, interaction and communication.

H.J.M. Hermans offers to set apart a) internal part of the self; b) external part of the self c) society - 'real others', people surrounding the human (Hermans, 2012).

H.J.M. Hermans offers to examine the dialogue in opposition to the monologue and includes in it:

o 'listening to each opinion;

o granting of space to everybody for expressing his/her experience and opinion;

o being interested in discovering of a possible non-understanding and wish to correct it;

o readiness to learn from each other based on mutual exchange' (Hermans, 2012).

H.R. Harre, one of the first discursive psychology theoreticians, notes that 'everyday language is the most important source of knowledge of the human psyche because the study of a person should take into account the inclusion of personality in a cultural and sociological context, not limited to the neural process description.' (Van Langenhove, 2010).

J. Potter and M. Wetherell formed the main points of discursive psychology in the book 'Discourse and Social Psychology: Beyond Attitudes and Behaviour':

o 'the principle of constructivity: discourse is constructed with words and constructs the social world itself.

o the principle of intentionality: discourse is focused on actions and social practices.

o the principle of situationality: discursive actions are derived from communicative, rhetorical, and institutional situations' (Potter \& Wetherell, 1987). 
This way, based on these provisions, psychological constructs are created, adjusted and used in the process of social contacts, and therefore in the dialogue process.

The subject continuously creates its identity in society that is why it cannot be forced to think separately from it.

It is argued that mental processes and discourse are of a communicative nature, and cognition is a set of symbolic language tools.

M. Buber gave the following definition of dialogue: 'I know three types of dialogue: genuine dialogue - no matter whether spoken or silent - where each of the participants really has in mind the other or others in their present and particular being and turns to them with the intention of establishing a living mutual relation between himself and them; technical dialogue, which is prompted solely by the need of objective understanding; disguised as dialogue monolog, in which two or several men, meeting in space, speak each with himself in strangely tortuous and circuitous ways and yet imagine they have escaped the torment of being thrown back on their own resources' (Buber, 1995).

J. Habermas distinguishes between 'implicit and explicit options for providing a claim of a vocal act to significance. The first occurs at the level of direct, 'naïve' communication. If consensus cannot be reached at this level, then as an alternative to stopping communication or using the language instrumentally (to influence partners), discourse is a way to test a conflicting claim to significance by arguing in a dialogue as a process aimed at achieving universally valid consensus' (Habermas, 1981).

D. Bohm gave the following definition to the dialogue: 'Dialogue can be considered as a free flow of meaning between people in communication, in the sense of a stream that flows between banks' (David Bohm Society, 2019). D. Bohm defined the following rules for conducting a dialogue: in the dialogue group we are not going to decide what to do about anything. There must be freedom to speak or not speak. Assumptions and judgments should be avoided. Dialogue should proceed as honestly and transparently as possible. Those who participate in reflection are based on the thoughts of another. He also stressed the importance of facilitator's participation in dialogue group that oversees the implementation of the above rules (Bohm, 2004).

Dialogue in the mediation is a tool for regaining the self-esteem of the persons involved in this process, instrument of inquiring into the situation, promotion of mutual respect and understanding and democracy (Portere \& Briede, 2019) and means of finding the solution. V. Portere and B. Briede highlighted the components and barriers to the dialogue that make up the dialogue of the participants and the mediation (Portere \& Briede, 2019).

Dialogue in the mediation process provides the following functions and stages:

o ensuring a positive atmosphere for mediation and relations between the participants in the conflict;

o obtaining information about the conflict, participants in the conflict, intentions, interests, needs and wishes of the participants;

o determining the level of conflict participants' dialogue possession and possible dialogue barriers, the unambiguous perception of indications;

o discussing possible options for achieving the participants' interests and solving the conflict;

o reaching final agreement between the participants in the conflict.

Recognizing dialogue function by questionnaire

While reviewing one of the dialogue types recognizing dialogue, the questionnaire method is used. Questions are composed using on the principles of Socrates's method (Clark \& Egan, 2015). The questionnaires provide verification of their own completion accuracy. The questionnaires composition includes questions that characterize the participants and the conflict, initial, guiding and final questions that help the mediator to mediate. Questionnaires are filled out by the participants in the conflict, participating in mediation or persons trained in mediation.

During the mediation with the help of questionnaires, it is possible to gather necessary information:

o to get acquainted with the conflict, participants in the conflict, which is used for further mediation;

$o$ to define the degree of unambiguity of perception of indications by the participants in the conflict;

o to define the level of dialogue possession by the participants in the conflict;

o to characterize the psychological constructs of the participants in the conflict that impede consensus achievement, the true interests and needs of the participants in the conflict;

o to define and establish strengths and weaknesses of different options for solving the conflict.

For the purposes of this article, the information collection and processing required to define the level of dialogue possession by the participants in the conflict or persons trained in mediation is considered.

While composing the questionnaires, the components and barriers of dialogue highlighted in the article 'Importance of Dialogue Nature in the Mediator's Competence' (Portere \& Briede, 2019) were used. 
To ensure the validity of the results, the composition of the questionnaires was checked for consistency by calculating Cronbaphs Alpha coefficient, taking 0.7 as the minimal acceptable value. To achieve an acceptable value of the coefficient, some components of questionnaires have been modified.

The respondents have the possibility to assess the usage of dialogue components and presence of psychological barriers by answering each question of the questionnaire: 'no', 'partly', 'yes'. For processing of questionnaires each answer has its own numerical designation (points): 'no' - 1, 'partly'-2, 'yes' -3 .

The verification of the reliability and conscientiousness of filling out the questionnaire was ensured by including control questions, which shouldn't have different or opposite answers, and setting the appropriate rules for respondents.

The questionnaires were processed using mathematical methods and the SPSS system (George \& Mallery, 2019) the internal consistency of the questions and emerging statistical patters (correlation) of the answers are analyzed.

As a result of processing the questionnaires, statistical coefficients that determine the internal consistency of indicators, descriptive statistics indicators, the normality of the distribution of statistical observations, the correlation degree of various indicators of the questionnaire were identified. The revealed patterns were used in the mediation process.

Total surveyed:

o persons wishing to learn mediation (future mediators) for subsequent use in personal and professional activities -26 people (there are 5 men and 21 women, aged 25-67 years, with secondary specialized and higher education).

o participants in the conflict during the mediation process of five mediations for the settlement of family relations in terms of joint communication in the family - 16 people ( 8 couples, of which 8 are men and 8 women, aged 35-50 years, with secondary specialized and higher education).

\section{Results and Discussion}

Let us identify the following types of dialogue in constructive mediation based on the analysis of mediation functions and stages, existing approaches and definitions of the concept 'dialogue':

o Dialogue, aimed at creating an atmosphere of cooperation in the mediation process;

o Recognizing dialogue, during which the mediator and the participants find out conflict data characteristics, come to a uniform understanding of its essence and legal grounds; it is the recognizing dialogue that can be conducted on the form of questionnaires; o Discursive dialogue (discourse), which is the main tool of reaching the agreement by the participants in the conflict. The mediator directs the discourse and, if it is necessary, sets its program;

o Crisis intervention dialogue, aimed at recognizing and analyzing emotions;

o Transformative dialogue, aimed at clarifying and drawing together the points of view, opinions and worldview of the participants in the conflict;

o Provocative dialogue in which the opinions and thoughts of one or both participants in the conflict are provoked to gain confidence in the stability and reliability of their thoughts and judgments.

Dialogue, aimed at creating an atmosphere of cooperation in the mediation process, is conducted by the mediator with the participants in the conflict to create a trusting atmosphere in the mediation process (affiliate communication), explain mediation rules, and achieve consensus between the participants on cooperation.

During the recognizing dialogue experience and methods of hermeneutics, theory of interpretation and understanding of texts, are used.

Discursive dialogue involves the exchange of evidence (arguments) to achieve the mediation aim. This type of dialogue is necessary to solve complicated conflicts.

During the transformative dialogue the principles laid down by D. Bohm are used when the participants try to achieve a common understanding of themselves, the partner and the situation, taking into account completely and equally the point of view of each participant.

During crisis intervention, dialogue is conducted to identify and discuss the feelings and emotions of the participants in the conflict, their causes, as well as possible consequences. The essence of such a dialogue is to show that the participants in the conflict are equally heard, accepted, understood by the mediator. It contributes to mutual acceptance and respect from the participants in the conflict.

Provocative dialogue, in contrast to crisis intervention, is aimed at identifying doubts and reasoning about the consistency of opinion about a conflict situation, it's a possible solution or personality and the character of the participant in the conflict, personal worldview and oneself.

Recognizing dialogue can be handled using the method of questionnaire. In this research, a questionnaire to determine the level of dialogue skills of conflict participants and persons trained in mediation has been conducted.

Used questionnaires details correspond to the dialogue components identified in the article 
'Importance of Dialogue Nature in the Mediator's Competence' (Portere \& Briede, 2019). The selection of components included in the questionnaires was carried out by checking their internal consistency using trial questionnaires and calculating the statistical coefficient Cronbaphs Alpha for completed answers. As a result, the following composition of components have been obtained:

o Evaluate the partner as a unique personality;

o Respecting of positions/ views;

o Emphatic understanding;

o Clear expression of information;

o Tolerance;

o Recognition of the partner's emotions;

o Searching for the sense of conversation;

o Responsibility for one's words uttered;

o Mutual equality of rights;

o Listening and hearing;

o Logic of the conversation;

o Readiness to obtain additional knowledge;

o Active listening;

o Readiness to change one's viewpoint, opinions, assumptions;

o Eye contact;

o Openness;

o Seriousness towards the dialogue process;

o Desire to find the truth;

o Desire to have the dialogue process;

o Seriousness towards the dialogue's partner and barriers hindering the dialogue:

o Lack of interest about the dialogue's theme;

o Lack of motivation to implement dialogue;

o Lack of time for dialogue;

o Fear of the dialogue process and/or its outcome;

o Fear of new information/ new knowledge;

o Fear that one's knowledge for conversation will be insufficient;

o Lack of respect towards the partner;

o Reluctance (fear) to change one's opinion, attitude, position; o Lack of empathy towards the partner;

o Non-conformity of values and/or intellect of the partners;

o Incomprehension of verbal and nonverbal communication of the partner;

o Phobias;

o Inability to concentrate for the dialogue process (internal circumstances);

o Various external disturbances/ circumstances.

Filling out of questionnaires was controlled by including in their composition control questions the answer to which must comply with certain rules. The answer to the question 'I evaluate the partner as a unique personality' must have at least 2 points, if answers to the questions 'Respecting of positions/ opinions', 'Tolerance', 'Mutual equality of rights' have 2 or 3 points. If these rules are not complied with, the mediator carries out additional preparation of the respondent how to correctly fill out questionnaires and performs a repeated filling of them.

While processing questionnaires filled out by people studying mediation, the decision on topics to be additionally explained in more detail as well as selection of appropriate training methodology can be made. The basis of this decision is the deviation of the average number of points obtained when answering the questions of the questionnaire: lower than the average in the case of questionnaires on the dialogue components and higher than the average in the case of questionnaires on dialogue barriers.

The results obtained while processing questionnaires filled out by people studying mediation, allows to conclude that the answers to the questions given in Table 1 are in correlation with each other. The degree of correlation is indicated in the table using the Spearman coefficient.

The Cronbaphs Alpha coefficient obtained during the processing of these questionnaires is 0.700 (for dialogue components) and 0.760 (for dialogue barriers), as well as a fairly large number of processed

\section{Correlated Questionnaire Questions}

\begin{tabular}{|l|l|c|}
\hline \multicolumn{1}{|c|}{$\begin{array}{c}\text { Questions about components and dialogue barriers } \\
\text { from the questionnaires }\end{array}$} & \multicolumn{1}{|c|}{ Questions with correlating relation } & $\begin{array}{c}\text { Spearman } \\
\text { correlation } \\
\text { coefficient }\end{array}$ \\
\hline Position / respect of beliefs & Mutual equality & 0.600 \\
Active listening & Listening and hearing & 0.588 \\
Seriousness in dialogue processes & Seriousness towards the dialogue partner & 0.843 \\
Lack of interest in dialogue & Lack of motivation for dialogue & 0.608 \\
Fear of new information & Phobias & 0.778 \\
Fear of lack of knowledge for a conversation & Phobias & 0.601 \\
Partner value and/or intellectual incompatibility & Incomprehension of partner communication & 0.673 \\
Inability to concentrate on a dialogue process & Different external disturbances/ circumstances & 0.605 \\
\hline
\end{tabular}


observations and practical experience of conducted mediations (including family mediations) allow using this regularity in the work of a mediator with participants of the conflict.

It can be hypothesized that an increase in the number of observations, obtained from people not involved in a conflict, will allow to enhance this list and, accordingly, help the mediator to conduct dialogue training during the mediation process.

Mediation participants fill in the questionnaire at the beginning and in the end of a mediation process. While processing the questionnaire, at the beginning of a mediation process the mediator pays attention to the opposite answers (point 1 and point 3 ) to questions that are statistically correlated based on the Table 1, as well as to the case when The Cronbaphs Alpha coefficient obtained by processing the results of the initial survey was less than 0 . Wherein each mediation participant is interpreted as a variable. As a result, the mediator determines which dialogue components need to be changed, which dialogue barriers need to be removed and, accordingly, selects methods for teaching dialogue.

Mediation practice has shown that if a preliminary questionnaire is conducted among conflict participants, certain answers can lead them to awareness of possibility to eliminate contradictions that caused the conflict and, consequently, to resolve the conflict without full process of mediation.

Accordingly in questionnaires used in this research, the answer 'no' to the questions 'Readiness to change one's viewpoint, opinions, assumptions' or 'yes' to the questions 'Lack of interest about the dialogue's theme', 'Lack of motivation to implement dialogue', 'Fear of the dialogue process and/or its outcome', 'Fear of new information/ new knowledge', 'Fear that one's knowledge for conversation will be insufficient' can be used for the above purpose.

To assess the mediation success after it has been carried out, the questionnaires are filled in. Comparison of the questionnaires completed during and after finishing the mediation process led to the conclusion that the success of mediation is also characterized by a certain degree of shift in the number of series obtained on the basis of an increase in the number of answers 'yes' (point 3) from the normal distribution while processing questionnaires with dialogue components and increasing the number of answers 'no' (point 1) while processing questionnaires with dialogue barriers (Table 1). The Cronbaphs Alpha coefficient obtained by processing these profiles is 0.849 (for dialogue components) and 0.709 (for dialogue barriers).

\section{Conclusions}

As a result of the work, the types of dialogue used in mediation and characterizing a constructive approach to it are highlighted:

o Dialogue aimed at creating an atmosphere of cooperation in the mediation process;

o Recognizing dialogue;

o Discursive dialogue (discourse);

o Crisis intervention dialogue;

o Transformative dialogue;

o Provocative dialogue.

Questionnaires for collecting information about dialogue components and barriers by participants of mediation and future mediators have been developed. The components and barriers of dialogue among mediation participants have been identified and evaluated.

The procedure for filling out and verifying the validity of questionnaires has been worked out.

The consistency of questions in the questionnaires is determined by calculating the Cronbapha Alpha coefficients. Values obtained from the questionnaires completed by individuals who are trained in mediation are 0.700 (for dialogue components) and 0.760 (for dialogue barriers); and from the ones completed by mediation participants are 0.849 (for dialogue components) and 0.709 (for dialogue barriers). This shows as sufficient consistency and reliability of the processed data.

Statistically processing the results of the questionnaires, completed by individuals who are being trained in mediation, the criteria of elaboration of their educational program has been determined and correlations between several questions in the questionnaires defined with the aim to be used for conflict parties during the mediation process. The conclusion is drawn about the necessity to further refine the revealed patterns based on the results of post-mediation process questioning as well as questionnaires completed by future mediators in the process of their training.

It is important to highlight the revealed possibility to bring the conflict participants to resolving the conflict based on questionnaire process without full process of mediation.

Questionnaires filled in after the successful completion of mediation, identified the evidence of the success of the mediation process.

\section{References}

Adler, E., \& Pouliot, V. (2011). International Practices. International Theory, 3(1), 1-36. DOI: 10.1017/ S175297191000031X.

Bahtin, М. (1979). Проблемь поетики Достоевского (Problems of Dostoevsky's Poetics). Moscow: Sovetskaja Rosija. (in Russian). 
Bohm, D. (2004). On Dialogue. Psychology Press. Routledge Classics. Retrieved March 3, 2020, from https:// books.google.lv/books?id=MGGF_oF_aY0C\&printsec $=$ frontcover\&source=gbs_ge_summary_r\&cad $=0$ $\# \mathrm{v}=$ onepage $\& \mathrm{q} \& \mathrm{f}=$ false.

Buber, М. (1995). Сборник 'Два образа веры. Диалог'(Collection 'Two Images of Faith. Dialogue'). Moscow: Respublika. (in Russian).

Clark, G.I., \& Egan, S.J. (2015). The Socratic Method in Cognitive Behavioural Therapy: A Narrative Review. Cognitive Therapy and Research, 39(6), 863-879. DOI: 10.1007/s10608-015-9707-3.

David Bohm Society. (2019). Bohm Dialogue. Retrieved March 3, 2020, from https://bohmdialogue. org/\#bohmdialogue.

George, D., \& Mallery, P. (2019). IBM SPSS Statistics 25 Step by Step: A Simple Guide and Reference. Taylor \& Francis. DOI: 10.4324/9781351033909.

Habermas, J. (1981). Theorie des kommunikativen Handelns (Theory of Communicative Action). Frankfurt am Main. ( in German)

Hermans, H.J.M. (2012). History, Main Tenets and Core Concepts of 'Dialogical Self' Theory // Handbook of Dialogical Self theory / Cambridge: Cambridge university press.

Kelly, G. (1991). The Psychology of Personal Constructs. Routledge in association with the Centre for Personal Construct Psychology.

Portere, V., \& Briede, B. (2019). Importance of Dialogue Nature in the Mediator's Competence. ENVIRONMENT. EDUCATION. PERSONALITY, 12, 146-151. DOI: 10.22616/REEP.2019.018.

Potter, J., \& Wetherell, M. (1987). Discourse and Social Psychology: Beyond Attitudes and Behavior. Retrieved March 3, 2020, from https://scholar.google.co.uk/scholar?as_sauthors=J+Potter\&as_q=Discourse + and $+\mathrm{S}$ ocial+Psychology\%3A+Beyond+Attitudes+and+Behaviour\&as_occt=title.

Soika, I. (2015). Entity of Dialogue in Career Guidance of Secondary Vocational Schools. ENVIRONMENT. EDUCATION. PERSONALITY ISSN. Retrieved March 3, 2020, from http://llufb.llu.lv/conference/ REEP/2015/Latvia-Univ-Agricult-REEP-2015proceedings-338-346.pdf.

Ulanovsky, A.M. (2009). Конструктивизм, радикальный конструктивизм, социальный конструктионизм: мир как интерпретация (Constructivism, Radical Constructivism, Social Constructionism: the World as an Interpretation). Question of Psychology, 2, 35-45. Retrieved March 3, 2020, from http://www.psy. msu.ru/people/ulanovsky/2009 Ulanovsky Constructivism, radical ..ctivism, social constructionism.pdf. (in Russian).

Van Langenhove, L. (2010). People and Societies: Rom Harré and Designing the Social sSciences. People and Societies: Rom Harré and Designing the Social Sciences. Routledge. DOI: 10.4324/9780203860885.

Yermolayeva, Y.V. (2015). The Main Characteristics of Dialogic Interaction (Defining the Actual Tasks of Pedagogic Dialog. The Education and Science Journal, 1(7), 18. DOI: 10.17853/1994-5639-2012-7-18-34. 